\title{
mTOR Silencing in Parkinson's Disease both in vitro and in vivo
}

\section{Mohamed Salama*}

Experimental Neurology Unit, Medical Experimental Research Center (MERC), Mansoura University, Mansoura, Egypt

*Corresponding author: Mohamed Salama, Experimental Neurology Unit, Medical Experimental Research Center (MERC), Mansoura University, Mansoura, Egypt, Tel: +201060556633; Email: toxicsalama@hotmail.com

Rec date: Apr-25-2015; Acc date: Apr-30-2015; Pub date: May-04-2015

Copyright: ( 2015 Salama M. This is an open-access article distributed under the terms of the Creative Commons Attribution License, which permits unrestricted use, distribution, and reproduction in any medium, provided the original author and source are credited.

\section{Letter to Editor}

Mammalian target of rapamycin (mTOR) is a serine/threonine kinase that regulates processes including mRNA translation, proliferation, and survival [1]. As a central element signaling cell growth and enhancing protein translation, (mTOR), when inhibited, induces autophagy. Moreover, as a critical feedback mechanism, reactivation of mTOR terminates autophagy and initiates lysosome reformation [2]. The phosphatidylinositiol 3-kinase (PI3K), AKT, mammalian target of rapamycin signaling pathway (PI3K/AKT/ mTOR) is frequently dysregulated in disorders of cell growth and survival, including a number of malignancies [3]. It seems that autophagy dysregulation, is not involved only in cancer as growing evidences support its possible role in aging diseases [4] especially neurodegenration. Recently, many researches showed the important role of such pathway in Parkinson's disease pathogenesis. UCH-L1 is the first deubiquitinating enzyme discovered. Mutations of UCH-L1 have been identified that impact the pathogenesis of Parkinson's disease $[5,6]$. Hussain and colleagues found that UCH-L1 impairs mTORC1 activity toward S6 kinase and 4EBP1 while increasing mTORC2 activity toward Akt. These effects are directly attributable to a dramatic rearrangement in mTOR complex assembly. UCH-L1 disrupts a complex between the DDB1-CUL4 ubiquitin ligase complex and raptor and counteracts DDB1-CUL4-mediated raptor ubiquitination. These events lead to mTORC1 dissolution and a secondary increase in mTORC2. The net result of such cascade of events is dysregulated autophagy. This can be linked to the recent findings of UCH-L1 capacity to modulate alpha-Synuclein in PD-like models [7]. Moreover, paraquat and maneb (herbicides known to induce PD) were found to inhibit autophagy through increasing the level of mTOR [8]. We believe these data offer an evidence that mTOR can play critical role in the pathogenesis of PD. Since the mammalian target of rapamycin has emerged as an attractive therapeutic target. Many agents have been designed to target the mTOR pathway, such as temsirolimus and everolimus. These have been used recently as anticancer therapy for different purposes $[9,10]$. However, we believe these mTOR inhibitors may serve alternatively as successful antiParkinsonian drug through enhancing autophagy.

\section{References}

1. Hussain S, Feldman AL, Das C, Ziesmer SC, Ansell SM, et al. (2013) Ubiquitin hydrolase UCH-L1 destabilizes mTOR complex 1 by antagonizing DDB1-CUL4-mediated ubiquitination of raptor. Mol Cell Biol 33: 1188-1197.

2. Kang R, Zeh HJ, Lotze MT, Tang D (2011) The Beclin 1 network regulates autophagy and apoptosis. Cell Death Differ 18: 571-580.

3. Polivka J Jr, Janku F (2014) Molecular targets for cancer therapy in the PI3K/AKT/mTOR pathway. Pharmacol Ther 142: 164-175.

4. Hu F, Liu F (2014) Targeting tissue-specific metabolic signaling pathways in aging: the promise and limitations. Protein Cell.

5. Maraganore DM, Lesnick TG, Elbaz A, Chartier-Harlin MC, Gasser T, et al. (2004) UCHL1 is a Parkinson's disease susceptibility gene. Ann Neurol 55: 512-521.

6. Ragland M, Hutter C, Zabetian C, Edwards K (2009) Association between the ubiquitin carboxyl-terminal esterase L1 gene (UCHL1) S18Y variant and Parkinson's Disease: a HuGE review and meta-analysis. Am J Epidemiol 170: 1344-1357.

7. Cartier AE, Ubhi K, Spencer B, Vazquez-Roque RA, Kosberg KA, et al. (2012) Differential effects of UCHL1 modulation on alpha-synuclein in PD-like models of alpha-synucleinopathy. PLoS One 7: e34713.

8. Wills J, Credle J, Oaks AW, Duka V, Lee JH, et al. (2012) Paraquat, but not maneb, induces synucleinopathy and tauopathy in striata of mice through inhibition of proteasomal and autophagic pathways. PLoS One 7: e30745.

9. Santoni M, Pantano F, Amantini C, Nabissi M, Conti A, et al. (2014) Emerging strategies to overcome the resistance to current mTOR inhibitors in renal cell carcinoma. Biochim Biophys Acta 1845: 221-231.

10. Barrett D, Brown VI, Grupp SA, Teachey DT (2012) Targeting the $\mathrm{PI} 3 \mathrm{~K} / \mathrm{AKT} / \mathrm{mTOR}$ signaling axis in children with hematologic malignancies. Paediatr Drugs 14: 299-316. 